clear weather or in restricted visibility using radar, because they meet all the questions that generally arise and in particular those posed by the collision problem.

\title{
REFERENCES
}

1 Garcia-Frías, J. (1960). Anti-collision radar sectors. This Journal, 13, 316.

2 García-Frías, J. (1965). The sector rule and the collision problem. This Journal, 18 , 141.

3 Garcia-Frías, J. (1970). The revision of the rules. This Journal, 23,7 I

\section{Distance by Vertical Angle}

\section{Charles H. Cotter}

SINCE the appearance of the note by Sayers ${ }^{1}$ in 1968 , followed by the publication of the table by Thompson ${ }^{2}$ in 1969 , and having myself described the method which was the subject of Sayers' and Thompson's communications, in a work ${ }^{3}$ on seamanship in 1962, I have searched for the origin of the method whereby an observer may find his distance off a ship or floating mark by means of a sextant observation of the vertical angle between the visible or sea horizon and the waterline of the ship or mark whose distance off is required.

It is interesting to note that the method is not utilized in Captain Lecky's famous tables 4 which were popular for many decades after their first publication in 1890 ; and that it does appear in a small, little-known, set of tables 5 by Commander S. H. S. Moxly, R.N., published in 1941 .

My search reveals that the original inventor of the method was Captain A. P. Ryder, R.N. ${ }^{6}$ Ryder was concerned not so much with the navigational problem per se but primarily with the naval gunner's problem of finding the range of an enemy ship with as little delay as possible. The value of the small handbook which he produced for the purpose was recognized by the Lords Commissioners of the Admiralty who purchased the whole of the first edition (1845) and ordered that a copy be placed on board every British man-of-war. In the preface to the second edition ( 1854 ) the author recorded, evidently with satisfaction, that his work had proved of 'service to cruizers on the Coast of Africa in chase of Slavers'.

Ryder referred to his method as the 'Horizon' method, namely 'To observe from the cross-trees, or other convenient place, the angle subtended between the horizon and the enemy's waterline.' He pointed out, rightly, that the higher the place of observation the less will any error in the observed angle affect the distance. The method was advertised as being suitable not only for Captains of guns on board ship but also for officers commanding fortresses (Gibraltar and Malta being mentioned specifically). In addition to this the distance from a target, a rock, a breaker or discoloured water, may be ascertained by the same method. Ryder also explained how the table he designed to facilitate the method could be used for determining the rising or dipping range of a light of known height.

To find the range of an enemy ship the angle of dip was to be added to the measured vertical angle. The resulting angle in degrees and minutes, and the height of the observer's eye above the sea in feet, are the arguments in Ryder's 
double-entry table giving the range in yards as respondent. An auxiliary table gives the error in the range in yards consequent upon an error of one foot in the height for each of the tabulated angles.

It appears that one of the standard methods for finding the range of an enemy ship required the measurement of the angle in the vertical plane between the waterline of the enemy ship and a point vertically below the observer who was required to be perched high above the deck on the cross-trees or a yard-arm. Ryder's table was designed to facilitate finding ranges by this method, a measured angle in this circumstance being used as argument direct, no dip correction being necessary. The difficulties that ranged themselves in opposition to this latter method must have prevented its ever having been of service.

\section{REFERENCES}

1 Sayers, P. H. (1968). Distance by vertical angle. This Journal, $21,83$.

2 Thompson, P. A. (1969). Distance-off by angle of depression. This Journal, 22, 141 .

3 Cotter, C. H. (1962). The Master and His Ship, London.

4 Lecky, S. T. S. (1890). The Danger Angle and Off-Shore Distance Tables, London.

5 Moxly, S. H. S. (1941). Coostal Tables for Use in Sight of Land, Glasgow.

6 Ryder, A. P. (Ist Edn 1845, 2nd Edn 1854, 3 rd Edn 1858). Methods of Ascertaining the Distance from Ships at Sea. London.

\section{A Note on Research Using Computers}

\section{A. Robinson}

LATELY there have been a number of articles and discussions in the Journal involving the use of computer programs to solve navigational problems. As one often involved in complex programming systems, I have some strong views on the subject. We are not an institution of programmers, and the few of us who have some programming knowledge, a very useful asset, are usually limited to one or possibly two languages. I would doubt if many people who could follow B. J. Moss's aLgol could also follow R. J. Turner's Fortran. Thus it seems strange that authors should go to the trouble of publishing the routines by which they do their calculations. After all, most of us are only interested in the method of attack and the answers rather than computer techniques.

In an article in the Forum, J. S. McKenzie criticizes Turner's forrran writing ability and then proceeds to complain as to his choice of language. True Turner's programs are not particularly efficient and obviously written with little consideration of speed or core requirements but perhaps McKenzie is a little harsh. Fully polishing programs is not really necessary when it is the answers that are really sought. After all, when the G.P. computer becomes commonplace, it will be practised programmers who will write the programs from specifications developed by the researchers into these navigational problems. It is the professional programmers who will take into account the speed and core requirements of the machine chosen for the purpose. It is the investigators in navigation who will provide the necessary means of solution. 